Table 1

\begin{tabular}{lccccc}
\hline Sh.-v. d.H score & \multicolumn{2}{c}{ MDA $(\mathrm{n}=25)$} & & \multicolumn{2}{c}{ No MDA $(\mathrm{n}=15)$} \\
\cline { 2 - 3 } \cline { 5 - 6 } & Baseline & After $1 \mathrm{yr}$. & & Baseline & After $1 \mathrm{yr}$. \\
\hline TES & $0[0-3]$ & $1^{*}[0-3]$ & & $3^{\#}[2-9]$ & $5^{\#}[2-11]$ \\
TNS & $88[70-108]$ & $88[71-108]$ & & $84[68-98]$ & $84[74-103]$ \\
TS Sh.-v.d. H. & $89[72-109]$ & $89^{*}[72-110]$ & & $93[81-106]$ & $93^{*}[83-115]$ \\
\hline
\end{tabular}

\#significant differences between groups (U-test, $p<0.05)$. * - significant differences into group (Wtest, $\mathrm{p}<0.05$ ).

Conclusions: In the Russian cohort of active EPsA pts erosion was found in more than half of cases. Active EPsA pts treated according to T2T strategy during 1 year in $72.5 \%$ did not show any radiographic progression, only a quarter of pts $(27.5 \%)$ had negative X-ray progression by the end of the study, regardless of the type of therapy. The pts who achieved MDA had less erosive progression. Disclosure of Interest: None declared

DOI: 10.1136/annrheumdis-2017-eular.3057

\section{SAT0452 INFLUENCE OF ANTIRHEUMATIC THERAPY ADMINISTERED IN ACCORDANCE WITH "TREAT TO TARGET" PRINCIPLES ON HEART RATE VARIABILITY AND CARDIOVASCULAR RISK FACTORS IN PATIENTS WITH ACTIVE EARLY PSORIATIC ARTHRITIS}

E. Markelova, D. Novikova, T. Korotaeva, E. Loginova, I. Kirillova, L. Denisov, D. Karateev. V.A. Nasonova Research Institute of Rheumatology, Moscow, Russian Federation

Background: Psoriatic arthritis (PsA) is an inflammatory arthropathy, which is associated with range of co-morbid diseases and risk factors, such as dyslipidemia, obesity, metabolic syndrome, cardiovascular disease (CVD). Lower heart rate variability (HRV) is a well-established risk factor for CVD and all-cause mortality in the general population.

Objectives: to study dynamic of traditional risk factors (TRF) of CVD and parameters of HRV during antirheumatic therapy, administered inaccordance with "Treat to target" principles in PsA pts.

Methods: 44 (F.-21) DMARD-naive PsA pts, according to the CASPAR criteria, age 36 [27; 46] years (yrs.), PsA duration - 6 [4; 8] yrs, DAS 4.06 [3.51; 4.74]. TRFs of CVD were assessed according to ESC (2016): arterial hypertension $(\mathrm{AH})-11(22.9 \%)$ pts, obesity (body mass index $>30 \mathrm{~kg} / \mathrm{m}^{2}$ ) $-11(22.9 \%)$, abdominal obesity - $14(29.2 \%)$, dyslipidemia $-31(64.5 \%)$, family history of early CVD - 6 (12.5\%), menopausal status - 5 (10.4\%), smoking - 16 (33.3\%). All pts were assessed for ECG, 24-h ECG monitoring, carotid ultrasound imaging. Antihypertensive therapy received all pts with $\mathrm{AH}$. Methotrexate (MT) therapy was started in all pts with an escalation of the dose up to $25 \mathrm{mg} /$ week subcutaneously. In case of no remission 3 months later, MT was added with biologic therapy: Adalimumab, Certolizumabpegol, Ustekinumab. 23 subjects were assessed after 18 months of therapy.

Results: After 18 months of therapy DAS and CRP level decreased significantly, $\mathrm{p}=0.001$. DAS remission was achieved in $82.6 \%$ of pts. The incidence rate of $\mathrm{AH}$ ( $39 \%$ vs $39 \%)$, obesity ( $30 \%$ vs $21 \%$ ), smokers (39\% vs $39 \%)$, menopausal status (17\% vs $17 \%)$, atherosclerotic plaques (39\% vs $39 \%)$, did not change significantly. High-density lipoproteins increased significantly from $1.2[1.1 ; 1.6]$ to $1.5[1.2$; $2.1] \mathrm{mmol} / \mathrm{l}, \mathrm{p}=0.03$. We didn't find significant differences between baseline and after treatment levels of total cholesterol/low-density lipoproteins level: from 5.2 $[4.6 ; 6.0]$ to $5.2[4.5 ; 5.9](p=0.47) \mathrm{mmol} / \mathrm{l}$ and from $3.4[2.8 ; 3.8]$ to $3.3[2.6 ; 3.6]$ $(\mathrm{p}=0.60) \mathrm{mmol} / \mathrm{l}$. HRVs parameters didn't change significant (table 1).

Table 1. HRV parameters in PsA pts baseline and after treatment

\begin{tabular}{lcc}
\hline Parameters & Baseline & 18 months \\
\hline MeanNN (ms) & $783[734 ; 883]$ & $803[773 ; 852]$ \\
SDNN $(\mathrm{ms})$ & $132[124 ; 159]$ & $147[129 ; 163]$ \\
SDNNi (ms) & $59[45 ; 69]$ & $61[42 ; 80]$ \\
SDANN (ms) & $121[101 ; 146]$ & $127[109 ; 160]$ \\
RMSSD $(\mathrm{ms})$ & $39[20 ; 50]$ & $33[18 ; 53]$ \\
pNN50 $(\%)$ & $13[2.6 ; 21]$ & $10.7[1.9 ; 22.7]$ \\
\hline
\end{tabular}

Data are present in median values and interquartile range, ${ }^{*} \mathrm{p}<0,05$ before and after 18 months treatment (nonparametric paired Wilcoxon test).

Conclusions: antirheumatic therapy of early PsA pts in accordance with "T2T" principles improves lipid profile but not HRVs parameters. Lower HRV is a risk factor for cardiovascular disease and mortality that demands the further studying its influence on the cardiovascular prognosis in PsA pts.

Disclosure of Interest: None declared

DOI: 10.1136/annrheumdis-2017-eular.5269

\section{SAT0453 EFFICACY OF USTEKINUMAB IN PSORIATIC ARTHRITIS PATIENTS BY PRIOR TREATMENT EXPOSURE AND DISEASE DURATION: DATA FROM PSUMMIT 1 AND PSUMMIT 2}

I. McInnes $^{1}$, S.D. Chakravarty ${ }^{2,3}$, G.J. Morgan ${ }^{3}$, I. Apaolaza ${ }^{4}$, S. Kafka ${ }^{3}$, E.C. Hsia ${ }^{5,6}$, M. Song ${ }^{5}$, Y. You ${ }^{5}$, A. Kavanaugh ${ }^{7}$. ${ }^{1}$ University of Glasgow, Glasgow, United Kingdom; ${ }^{2}$ Drexel University College of Medicine, Philadelphia; ${ }^{3}$ Janssen Scientific Affairs, LLC, Horsham, United States, ${ }^{4}$ Janssen Biologics BV
Leiden, Netherlands; ${ }^{5}$ Janssen Research \& Development, LLC, Spring House; ${ }^{6}$ University of Pennsylvania, Philadelphia; ${ }^{7}$ University of California, San Diego, la Jolla, United States

Background: PSUMMIT 1 and PSUMMIT 2 were Phase 3 trials of ustekinumab (UST) in adults with PsA.

Objectives: Evaluate the efficacy of UST by prior treatment exposure and disease duration in PsA patients (pts) in PSUMMIT 1 and 2.

Methods: Pts had active PsA ( $\geq 5$ swollen, $\geq 5$ tender joints, CRP $\geq 3.0 \mathrm{mg} / \mathrm{dL}$,) for $\geq 6$ mos despite treatment with DMARDs and/or NSAIDs (PSUMMIT 1) or DMARDs, NSAIDs, and/or anti-tumor necrosis factor (TNF) agents (PSUMMIT 2). In both studies, pts were randomized to SC injections of placebo (PBO) or UST $45 \mathrm{mg}$ or $90 \mathrm{mg}$ at wks 0,4 and every 12 wks. PBO pts crossed over to UST $45 \mathrm{mg}$ at wk 24. At wk 16, early escape (PBO -> UST45mg; UST45mg -> UST90mg; UST90mg $\rightarrow>$ UST90mg) was possible. Stable doses of MTX were allowed. Pooled data from both PSUMMIT 1 and 2 were analyzed. Efficacy assessments included ACR response, DAS28-CRP response, DAS28-CRP remission (score $<2.6$ ), changes in enthesitis (modified MASES index) and dactylitis scores, and total van der Heijde-Sharp (vdH-S) score for radiographic progression. Pts who were anti-TNF-naïve, MTX- and anti-TNF-naïve, all DMARD- and anti-TNF-naïve were evaluated. ACR response at wks 4 and 16 to assess for early efficacy was also evaluated for anti-TNF-naïve pts with PsA duration $<1$ year, $\geq 1$ to $<3$ years, and $\geq 3$ years.

Results: In the pooled data, 747 pts were anti-TNF-naïve (53.8\% were male; mean age $=47$ years); 179 pts were MTX- and anti-TNF-naïve $(63.7 \%$ were male mean age $=47$ years); 146 pts were all DMARD- and anti-TNF-naïve $(61.0 \%$ male; mean age $=46$ years). In all three prior treatment populations significantly greater proportions of pts in the combined UST group vS PBO achieved an ACR20, ACR50, or ACR70 at wk 24. (Table). Similarly, greater proportions of pts in the combined UST group had DAS28-CRP response or remission vs PBO across all three prior treatment populations. In anti-TNF-naïve pts, improvements in enthesitis and dactylitis were significantly greater in the combined UST group vs $\mathrm{PBO}$, and mean change in total $\mathrm{vdH}$-S score was significantly greater for pts in the PBO group than the combined UST group; comparable trends were observed for the MTX- and anti-TNF-naïve pts and all DMARD- and anti-TNF-naïve pts, but did not reach statistical significance due to the smaller sample sizes in both subgroups. Among anti-TNF-naïve pts treated with UST, ACR20/50/70 response rates were similar across different PsA disease duration groups at early time-points (either wk4 or wk16).

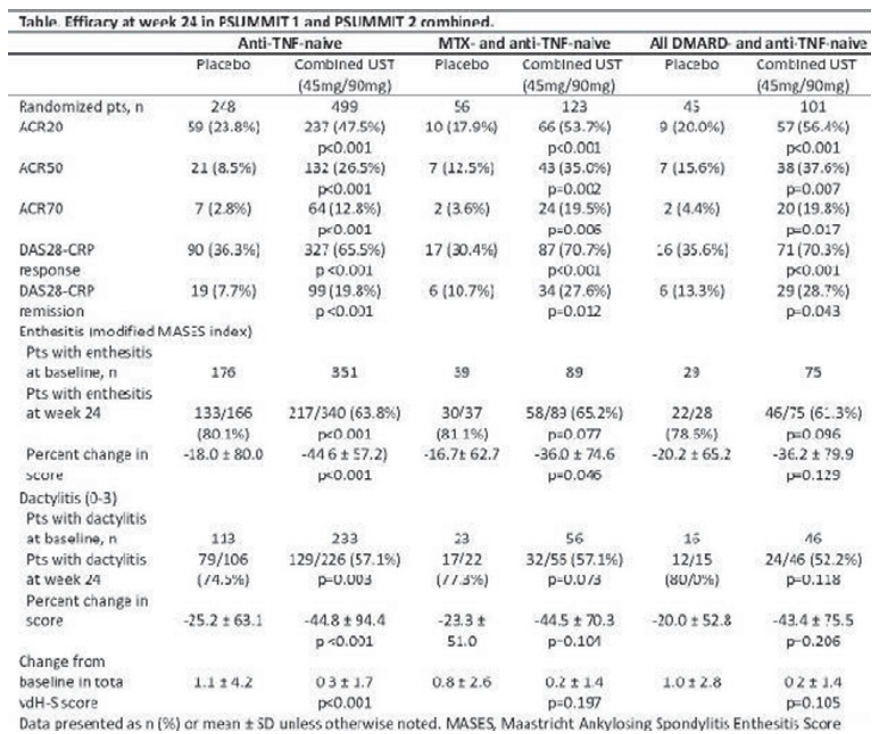

Conclusions: UST-treated patients had greater improvements in signs and symptoms of PsA regardless of prior treatment exposure and disease duration. Disclosure of Interest: I. McInnes Consultant for: Janssen Research \& Development, LLC, S. Chakravarty Employee of: Janssen Scientific Affairs, LLC, G. Morgan Employee of: Janssen Scientific Affairs, LLC, I. Apaolaza Employee of: Janssen Biologics, BV, S. Kafka Employee of: Janssen Scientific Affairs, LLC, E. Hsia Employee of: Janssen Research \& Development, LLC, M. Song Employee of: Janssen Research \& Development, LLC, Y. You Employee of: Janssen Research \& Development, LLC, A. Kavanaugh Consultant for: Janssen Research \& Development, LLC

DOI: 10.1136/annrheumdis-2017-eular.4538 